\title{
Price Clustering in Individual Equity Options: Moneyness, Maturity and Price Level
}

\begin{abstract}
:
Equity options have a significant influence on the price discovery process. This paper presents unique evidence of substantial price clustering in individual equity options contracts. A particular contribution arises from investigating competing hypotheses on the roles of moneyness and maturity as determinants of option price clustering. We assert that options price clustering can be decomposed to price level, moneyness and maturity effects. After controlling for other factors, price clustering has an inverse relation with time to maturity. This supports the negotiation hypothesis, but not the price resolution hypothesis. Price clustering also tends to be inversely related to moneyness. This effect is linked to the intrinsic value component of option price. Both the maturity and moneyness effects act in an opposite direction to what would be anticipated on the basis of price level alone, hence these two effects are identified as additional influences on option price clustering. It is also found that the designated market maker scheme at NYSE Euronext-LIFFE has little influence on trade price clustering.
\end{abstract}

Keywords: High frequency data, Equity options, Price clustering, LIFFE JEL: G14, G12 


\section{INTRODUCTION}

Price clustering refers to the non-uniform distribution of final price digits in financial assets and reflects the tendency of market participants to use a coarser set of prices than that dictated by minimum tick size restrictions. Theory suggests that price clustering in financial markets could be a function of price uncertainties (Ball et al., 1985, Aitken et al., 1996), could arise from a need to minimise trade negotiation costs (Harris, 1991), or could reflect investors' attraction to particular numbers (Goodhart and Curcio, 1991) and, given the existence of market makers, the tendency of the latter to maintain wider spreads (Christie and Schultz, 1994). In derivatives markets, empirical studies are mainly focused on the futures markets (e.g. ap Gwilym et al., 1998a,b; Schwartz et al., 2004) and the sparse evidence on options contracts (ap Gwilym et al., 1998a; Capelle-Blancard and Chaudhury, 2007; Cheng et al., 2005) is restricted to stock index contracts. Finally, Ni et al. (2005) show that option trading induces stock price clustering. In particular, the authors show that stock prices for optionable stocks cluster around option strike prices at expiration dates, altering stock returns only for stocks that have tradable options. It is found that hedge rebalancing and stock price manipulation contribute significantly to price clustering in the underlying stocks at option expiration dates.

ap Gwilym et al. (1998a) report extreme price clustering in the FTSE100 index options contract traded at Euronext-LIFFE, which also tends to increase with price level. Low priced, out-of-the-money, near-to-mature contracts display less price clustering. Capelle-Blancard and Chaudhury (2007) show that price clustering in the CAC40 index option contract increases with the price level. Their findings on the 
effects of moneyness and maturity on price clustering are inconclusive. ${ }^{1}$ The findings of ap Gwilym et al. (1998a) and Capelle-Blancard and Chaudhury (2007) offer more support for the attraction hypothesis than for other theories on price clustering. Cheng et al. (2005) report that quote and bid-ask spread clustering on the Hang Seng index futures and options decreased following a switch to electronic trading. The implementation of a relatively low tick size increased execution efficiency and transparency, allowing traders to use the full range of available prices.

Individual equity options contracts have been repeatedly praised for their contribution to price discovery and are found to lead the process of reflecting new information in market prices (see Hull, 2008). This study offers an explanation of price clustering in individual equity option contracts that links price clustering with the intrinsic value and time value inherent in options. In contrast to equity markets, where price level is the key determinant of price clustering, we argue that determinants of options price clustering can be decomposed to price level, moneyness and maturity effects. It is hypothesised that price clustering in options contracts is the price of liquidity, ${ }^{2}$ which has very important implications for the price discovery process. This also offers an approach whereby the negotiation and price resolution hypotheses can be tested for options contracts.

\footnotetext{
${ }^{1}$ In Capelle-Blancard and Chaudhury (2007), clustering is positively related to maturity, but this is not statistically significant when the effect of a change in tick size is accounted for. The relation between clustering and moneyness is also insignificant after controlling for the effect of a change in tick size.

${ }^{2}$ The fact that price clustering can be modelled as a factor rather than the outcome of "order imbalances" is documented in McGroarty et al. (2007). They use foreign exchange data, and no such study exists for options markets.
} 
We find that options price clustering is strongly influenced by options contract characteristics. Clustering is inversely related to maturity. Prices tend to be clustered for the short-maturity contracts, because the need to trade in options contracts increases as the expiry date approaches (particularly to close out positions prior to maturity or to rollover exposure to the next maturity). We suggest that a revised version of the negotiation hypothesis tends to better explain the price clusteringmaturity relationship in individual equity options than does the price resolution hypothesis. Price clustering also tends to be inversely related to moneyness. This effect is linked to the intrinsic value component of the option price, and specifically that less clustering occurs when valuation is less "hazy" (see Aitken et al., 1996). Both the maturity and moneyness effects act in an opposite direction to what would be anticipated on the basis of price level alone, hence these two effects are identified as additional influences on price clustering for options. Also, the designated market maker scheme at NYSE Euronext-LIFFE has little influence on price clustering.

The remainder of this paper is structured as follows: The next section discusses our hypotheses for options price clustering. The "Data and Methodology" section outlines the data and methodological issues and the "Empirical Results" section presents and discusses the results. The "Conclusion" section summarises and concludes the paper.

\section{HYPOTHESES FOR PRICE CLUSTERING IN OPTIONS}

\section{CONTRACTS}

According to the negotiation hypothesis (Harris, 1991), price clustering is the result of the trade-off between reduced negotiation costs and increased price transparency. 
Also, the price resolution hypothesis (Ball et al., 1985) argues that price clustering is a function of the amount of information about the true price of the asset that is available in the market. Thus, the less information about the asset's value, the more severe will be the degree of price clustering. The above hypotheses imply that rounding of traded and quoted prices can be seen as primarily dictated by price level; hence, it is generally accepted that price clustering is a positive function of the price level of assets, a finding that nests both the negotiation and the price resolution hypotheses.

In equity markets, price clustering is one-dimensional with regard to this price level effect. In contrast, options prices have time value and intrinsic value components. Hence, in options markets, price clustering is multi-dimensional and has embedded time-specific characteristics. It is thus possible to determine an indirect time determinant of clustering, the importance of which lies in the fact that it cannot be captured by the price level effect. First, the specification of maturity dates for each option contract introduces the concept of a time-effect in price clustering. The further a contract is from maturity, the greater the time value (all else being equal). Hence, observed price clustering should adhere to a time based pattern, where longer to mature contracts display different clustering to near-to-mature contracts because, apart from the price level effect, greater information uncertainties are embedded in the longer to mature contracts. Second, options contracts that are deep-out-of-the-money essentially have only time-value, while in-the-money options are more valuable thus trade at higher price levels. As above, it is hypothesized that failing to treat 
moneyness as separate from the price level effect leads to a crowding out of the separate influence of the variability in moneyness. ${ }^{3}$

Based on the above considerations, the existing price clustering hypotheses should be regarded as insufficiently specific for options. In order to reflect options price clustering, there is a need to make important adjustments to the original hypotheses based on the maturity and moneyness elements.

In option contracts, the negotiation hypothesis also has a time dimension. Given that European-style options can be exercised only at the expiration dates, the trading volume of an option contract is maximised on the expiration day. So, there is a climax of interest for these option contracts. On the other hand, for American-style options, such interest is more dispersed over time, and a trading peak, if such a peak exists, should be less pronounced. In Table I, we document that both volume and trading frequency increase as expiration approaches. The latter implies that under a volume-based explanation of price clustering, prices will cluster less for the shortermaturity contracts. On the other hand, the negotiation hypothesis assumes that traders will use a coarser set of prices as the urgency to trade increases (Harris, 1991). Consequently, because the negotiation cost hypothesis is associated with investors' urgency to trade, an adjustment is made in the hypothesis and we expect to observe option prices to cluster more for short maturities.

$* * * *$ Insert Table I about here $* * *$

\footnotetext{
${ }^{3}$ To some extent, this argument is related to Schwartz et al. (2004) where price clustering differences in front- and back-month futures contracts are found after controlling for the large differences in volume. However, the propositions in our study do not relate to trading volume as a dominant influence.
} 
The price resolution hypothesis assumes that price clustering reflects the optimal degree of price resolution. For options, this implies that the approach of contract expiry and the resultant increased attention should improve the valuation of individual equity options. The underlying assumption for the above is that intrinsic value is a larger proportion of option price for short-maturity contracts than for longer maturities. In Table II, we decompose the option price to intrinsic value and time value. The intrinsic value (IV) component is calculated as the present value of the difference between the underlying asset price and the exercise (expressed as a proportion of the option price). The time value (TV) component is calculated as the difference between the present value of intrinsic value and the current option price. ${ }^{4}$ Table II shows that, when controlling for the moneyness effect, IV is a higher proportion of the option price for the shorter-to-mature contracts. Consequently, under the price resolution hypothesis, price clustering should be less evident for the short maturity contracts, even after controlling for differences in the price level. We note that from Table I, a volume-based explanation would imply less clustering for out-ofthe-money options.

**** Insert Table II about here***

\footnotetext{
${ }^{4}$ The present value of the intrinsic value (IV) component is calculated as follows: IV $=\left(S_{T}-X\right) e^{-r T}$ for calls and IV $=\left(\mathrm{X}-\mathrm{S}_{\mathrm{T}}\right) \mathrm{e}^{-\mathrm{rT}}$ for puts, where $\mathrm{S}_{\mathrm{T}}$ refers to the underlying asset price, $\mathrm{X}$ is the exercise price, $\mathrm{r}$ is the risk-free rate (90 day T-Bill) and $\mathrm{T}$ is the days to maturity (divided by 365 ). This figure is then expressed as a proportion of the current option price. The time value (TV) component is calculated as the residual of the current option price less the intrinsic value.
} 
Moneyness is reflected in the price level of options contracts. In-the-money options contracts trade at higher price levels (all else being equal), hence one might expect greater price clustering (as implied by Cheng at al., 2005). ap Gwilym et al. (1998) report that keeping maturity constant, less clustering is associated with in-themoney index options. When moneyness is greater, the intrinsic value is a larger proportion of the option's value (documented in Table II). This implies a greater certainty of value (or less 'haziness' as in Aitken et al, 1996), which could lead to less price clustering. This effect would be independent of the price level or any volume/liquidity considerations.

The above main testable hypotheses are presented in Table III. The negotiation hypothesis implies that price clustering increases with trade size and price level (Harris, 1991). The price resolution hypothesis implies that greater information leads to less price clustering (Ball et al., 1985). In this paper, we assert that as maturity interacts with the price level, the negotiation and the price resolution hypotheses give opposite predictions about the nature of the relationship between price clustering and maturity. Hence, the negotiation hypothesis in options contracts implies that short maturity contracts will exhibit more clustering as a result of increased urgency to trade. On the other hand, the price resolution hypothesis predicts that assets close to maturity will be priced more reliably, hence, less price clustering is anticipated.

Cheng et al. (2005) show that price clustering increases for in-the-money contracts, reflecting higher price levels. However, Cheng et al. (2005) use the option price instead of the underlying price as only an approximation to moneyness and fail to control for the price level effect in their model, hence this hypothesis can only be tentatively suggested as the most appropriate. In contrast, we hypothesize that as the intrinsic value of options increases for the more in-the-money options, price clustering 
will decrease due to less price "haziness", after controlling for the price level effect. Volume based explanations of the clustering-maturity and the clustering-moneyness relationships would be more consistent with Hypotheses 2a and 2b (as implied by Table I), i.e. positive signs would be expected.

**** Insert Table III about here***

\section{DATA AND METHODOLOGY}

Two high frequency datasets are employed. The first consists of all trades and quotes posted on individual equity option contracts at the NYSE-Euronext London International Financial Futures Exchange (Euronext-LIFFE) during 2005. Trading in Euronext-LIFFE is facilitated through LIFFE CONNECT ${ }^{\circledR}$, an electronic market, which offers direct access for investors. Trading on LIFFE CONNECT ${ }^{\circledR}$ also occurs via designated market makers. The second dataset includes all trades and quotes posted on the London Stock Exchange (LSE) during 2005..$^{5}$ The LSE data are supplied in CD format, whereas access to Euronext-LIFFE data is via NextHistory (online access by subscription). In order to control for stale and non-synchronous pricing problems, the most heavily traded assets are selected. Specifically, option assets that report more than 1500 trades during 2005 are selected, leading to a sample based on 28 equity options. In a similar manner to Chakravarty et al. (2004), for an asset that has traded more than 1500 times over the calendar year, all the

\footnotetext{
${ }^{5}$ LSE trade data are appropriate for the calculation of the moneyness measure for equity options.
} 
maturity/strike price contracts are included, which allows us to study price clustering across multiple moneyness and maturity levels. ${ }^{6,7}$

****Insert Table IV about here***

Table IV presents the descriptive statistics for this dataset. The data are classified according to the minimum tick size. The maturity and moneyness effects stretch the price range of contracts from the minimum tick size to a maximum price of 1332.5p. ${ }^{8}$ When the minimum tick is $\mathrm{xx} .25 \mathrm{p}$, one would expect the following occurrence of price endings in descending order: xx.00, xx.50, (xx.75 and xx.25). For the options with a minimum tick size of xx.50p, price clustering in integers should be even more pronounced.

\footnotetext{
${ }^{6}$ Thirty-one equity options met the criteria. Two firms were dropped from the sample owing to price distortions caused by restructuring. One firm was dropped due to ambiguous/conflicting information provided by Euronext-LIFFE and the LSE. In line with the definition of price clustering used, prices less than 50p are deleted from the sample.

${ }^{7}$ Screening out the most illiquid assets does not induce any sample selection bias, especially with regard to the inclusion of the further-to-mature and deep-in and deep-out of the money contracts. In fact, the sample that meets the transaction frequency criterion includes higher proportions of contracts with high moneyness levels and long maturity dates than the excluded assets (results available upon request).

${ }^{8}$ Summary statistics on the detailed distribution of prices taking into account all exercise prices and maturity dates would be unrealistic because the number of combinations of contracts in the dataset is greater than 17,000 .
} 
In order to evaluate the extent of price clustering in equity option contracts, the $x^{2}$ goodness-of-fit test statistic is used. The statistic measures how well the observed prices reflect the expected last digit distribution and is computed as follows:

$$
x^{2}=\sum_{i=1}^{k} \frac{\left(n_{i}-\sum_{j=1}^{k} n_{j}\right)^{2}}{\sum_{j=1}^{k} n_{j}}
$$

Where $n_{i(j)}=$ number of observations at final digit $i(j)$ with $k$ possible ticks. Under the hull hypothesis of no price clustering, $x^{2}$ would give a value close to zero.

In addition, a regression model based on hourly data is estimated to identify the determinants of price clustering in options contracts. The dependent variable, Clust, is the percentage of price observations at integers. In order to control for differences in the tick size, different regressions are estimated for the two tick sizes. Also, different regressions are employed for call and put options, as well as for quotes and trades, hence a total of eight regressions are estimated.

We measure moneyness $(M O N)$ using the underlying stock prices as follows:

Moneyness $($ calls $)=\left(S_{i}-X_{i}\right) X_{i}^{-1}$

Moneyness $($ puts $)=-\left(\left(S_{i}-X_{i}\right) X_{i}^{-1}\right)$

Where $\mathrm{S}$ is the contemporaneous price of the underlying stock. The denominator controls for the different price levels across option contracts. 
The proxies for price level $(P L)$ and trade size $(T S)$ are the average trade price and trade size per hourly interval respectively (see ap Gwilym et al., 1998a). As price clustering is assumed to increase with the price level $(P L)$, a positive relationship is anticipated. In contrast, the negotiation cost hypothesis implies that there is an inverse relationship between trade size $(T S)$ and price clustering. Also, if larger firms are more efficiently priced, they will experience less price clustering (Harris, 1991). Firm size $(F S)$ is proxied by each firm's market capitalization, which is obtained from DataStream.

The volatility ( $\mathrm{Vol}$ ) estimate is the standard deviation of the natural logarithm of returns per asset and should be positively related to price clustering (Harris, 1991). In general, the calculation follows the procedure introduced by Sheikh and Ronn (1994). Returns are calculated only for the at-the-money, nearest to mature contracts. The ask prices are used (see Bollerslev and Melvin, 1994). At each time interval, the first ask price is obtained. For the closing return calculation, the last ask price of the day is obtained. The closing ask price and the first ask quote of the next day are used for the computation of the opening returns. The procedure adopted is the following: at every hourly interval $i$ the first ask price is obtained. Then, at the next hourly time interval $i+1$, the ask price with the same strike price is obtained. The logarithmic return is calculated from these two prices. If however, there is no ask with the same strike price on the next interval $i+1$, we search for the last available ask price in interval $i$ with the required strike price. When the returns for the intervals $i$ and $i+1$ are calculated, the same procedure is repeated for the next interval $i+2$. Different strike prices can meet the 'at-the-money' criteria for a given contract in consecutive intervals, and this is accounted for. 
Transaction frequency is used as a proxy of information asymmetries and should be negatively related to price clustering because higher frequencies will reveal more about the true value of the assets (Harris, 1991). TF is measured as the inverse square root of the number of transactions per day.

A dummy variable is used to proxy for the liquidity schemes provided by Euronext-LIFFE (see also Anand and Weaver, 2006). ${ }^{9}$ The dummy variable $(D M M)$ equals 1 if the contract is supported by both Designated and Primary Market Makers and $O$ if the contract is only supported by Primary Market Makers. A negative coefficient for DMM would support the hypothesis that DMMs assist in price discovery i.e. that a finer price set is observed.

ap Gwilym et al. (1998a) note that in the open outcry environment of (preelectronic trading) Euronext-LIFFE, price clustering might actually be inversely correlated with busy trading periods such as the open and close of the market. In order to test the above hypothesis in the hybrid trading structure of the equity options market, two dummy variables are introduced: the open dummy $(O D)$ equals 1 at the opening interval (08:00 to 08:30) of the day and zero at all other times, and a closing dummy $(C D)$ similarly constructed is used for the closing interval (15:30 to $16: 25)$.

The following model is estimated:

\footnotetext{
${ }^{9}$ At Euronext-LIFFE, the continuity of quotes and competition in spreads is supported by Primary Market Makers. All individual equity options contracts are supported by a Primary Market Maker. Further, the Designated Market Maker Scheme intends to complement the Primary Market Makers. Their function is to provide spreads in generally larger quote sizes than are supported by Primary Market Makers (see Anand and Weaver, 2006).
} 


$$
\begin{aligned}
\text { Clust }_{i t y x} & =\alpha_{1}+a_{2} \operatorname{MON}_{i t x}+a_{3} \operatorname{TTM}_{i z x}+a_{4} \mathrm{PL}_{i z-1} \\
& +a_{5} F S_{i z}+a_{6} \operatorname{Vol}_{i t x}+a_{7} T S_{i t x}+a_{8} \mathrm{DMM}_{i} \\
& +a_{9} T F_{i t x}+a_{10} \mathrm{OD}_{t}+a_{11} C D_{t}+\varepsilon_{i t y x}
\end{aligned}
$$

Where $i=$ firm, $t=$ intraday interval, $z=$ daily price, $y=$ quote/trade, $x=$ call/put. The dependent variable, Clustityx, is the percentage of price observations at integers at each hourly time interval $t(t=1, \ldots 2052)$, for $i=28$ firms and is different for $x=$ calls or puts and $y=$ quotes or trades ${ }^{10}$ As denoted by the subscripts, the independent variables are calculated as appropriate. $M O N$ is the average moneyness measure per contract at every interval; TTM is the time to maturity for options traded at each time interval; $P L$ is the average trade price level at each time interval per contract; $F S$ denotes the firm size as the natural log of market capitalization based on daily closing prices for each firm; $V O L$ denotes volatility for the at-the-money, nearest-to-mature contract; $T S$ is the average trade size at each time interval per contract; $D M M$ is the Designated Market Maker dummy; $T F$ denotes the transaction frequency at each time interval as the inverse square root of the number of transactions per day for each call and put contract. $O D$ and $C D$ are the open and close dummies respectively.

\footnotetext{
${ }^{10}$ Time intervals with no price data are omitted. The total number of intervals for the 28 firms is 57,456 , hence, there is substantial variability in the number of observations between the regressions (see Table IX).
} 


\section{EMPIRICAL RESULTS}

This section documents the extent of price clustering in individual equity options. The first part gives a detailed description of the results at a univariate level, while the second part reports on the multivariate regression models.

\section{Univariate Analysis}

Table $\mathrm{V}$ presents information on the extent of price clustering in equity option contracts. $^{11}$

$$
* * * * \text { Insert Table } \mathrm{V} \text { about here } * * *
$$

It is clear that there is a substantial variation across individual assets and between quotes and trades. For assets with a minimum tick of xx.50, quote price clustering ranges from $51.79 \%$ to $80.22 \%$ and trade price clustering is between $55.48 \%$ and $67.57 \%$. For assets with a tick size of xx.25, quote price clustering varies from $26.26 \%$ to $40.88 \%$. For the trades, price clustering ranges from $28.84 \%$ to $39.86 \%$. The $\chi^{2}$ test statistic rejects the hypothesis of no trade price clustering for 19 assets at the $95 \%$ significance level. For quotes, price clustering is statistically significant for 16 assets at the $95 \%$ level.

Table VI, Panel 1, presents the distribution of xx.00 prices for all assets at both minimum tick sizes. For the small tick size (xx.25), clustering within the lowest quartile of price is $28.38 \%$ for quotes and $33.34 \%$ for trades, whereas for the largest quartile, clustering is $42.31 \%$ for quotes and $57.14 \%$ for trades. For the xx.50 tick

\footnotetext{
${ }^{11}$ Throughout this paper an integer definition of price clustering is used.
} 
size, quotes are clustered at $50.91 \%$ and $58.94 \%$ for quotes and trades for the smallest quartile respectively. For the largest quartile, clustering is $57.10 \%$ for quotes and $67.48 \%$ for trades.

****Insert Table VI about here***

For the xx.25 tick size, it is clear that Harris' (1991) negotiation hypothesis holds, whereby price clustering increases substantially as the price level increases. This effect is more pronounced for trades. Thus, if excess price clustering is defined as excess percentage of integer prices over the optimal percentage, ${ }^{12}$ then excess trade clustering for a tick of xx.25 reaches $128 \%$ at the highest price levels. For the xx.50 tick size, trades follow the same increasing clustering pattern, yet the excess clustering figure is $34 \%$. The latter finding in Table VI might actually reflect the fact that the tick size is restricting and prohibits trades at a smaller price increment.

Table VI, Panel 2, presents the distribution of price clustering at integers at different trade size quartiles. For the smaller tick size (xx.25), the results on quotes support the negotiation hypothesis, with price clustering at integers almost doubled for the largest size quartile. The negotiation theory also holds for quotes at the xx.50 minimum tick, even though the difference for the largest size quartile is not as large as for the smaller tick. For trades, Table VI reports a different clustering pattern. In particular, for the tick size of xx.25, price clustering in integers decreases with trade size (see also Aitken et al, 1996), while for the larger tick, the negotiation hypothesis continues to hold (marginally).

\footnotetext{
${ }^{12}$ Excess $=((\%$ of clustering - uniform $) /($ uniform $)) * 100$.
} 
Table VII presents data for price clustering on the expiration day, the week preceding the expiration day and the remaining dates. This distinction is made on the basis of the increase in volume and on the increased urgency to trade on the expiration date (see Table I and also Chung and Chiang, 2006). It is assumed that the build-up of interest is captured in the calendar week prior to the expiration day. Table VII shows that, when the tick is xx.25, price clustering peaks on the expiration day. Also, price clustering increases monotonically for quotes as the expiration day approaches and the $x^{2}$ statistic captures this increasing trend. A similar finding applies for quotes under the xx.50 tick size. Trade price clustering for both tick sizes falls marginally in the expiration week. ${ }^{13}$

****Insert Table VII about here***

Figure 1 presents the intraday clustering pattern for quotes and trades classified by different tick sizes. Figure 1a (for tick size of xx.25) is consistent with previous research on intraday patterns in price clustering (Ohta, 2006; Schwartz et al., 2004). Quotes follow a typical U-shaped pattern. Trades also have a high level of clustering at the market open, but the pattern is more variable during the trading day. These high degrees of clustering at the market open are partially attributed to the price uncertainty that prevails (see Ohta, 2006). A different pattern is observed for the larger tick size (xx.50), as clustering for quotes at the market open is relatively low and increases during the first trading hour before it takes the standard U-shaped

\footnotetext{
${ }^{13}$ It is also found that price clustering on expiration Fridays is greater than for non-expiration Fridays (results not presented in the interests of brevity).
} 
pattern for the remainder of the trading day. As with the smaller tick, trades are more clustered at the beginning of the day and other peaks are found during the trading day.

****Insert Figure 1 about here***

Table VIII presents the percentages of integer price clustering across call/put and trade types classified by maturity and moneyness. Since at this point we do not control for the price level effect, we expect this effect to predominate. This is true when differences within maturities are considered. It is found that for the nearer-tomaturity contracts, quote price clustering is strongly influenced by moneyness. Thus, prices for in-the-money contracts are more clustered than those for at-the-money contracts and prices for at-the-money contracts are more clustered than those for outof-the-money contracts. When maturity is more distant, the price clustering differences that are attributable to moneyness diminish. For the longest-to-mature contracts, price clustering levels are relatively consistent across differing moneyness. For trades, the evidence on this point is less consistent, but a moneyness effect is present in many cases.

**** Insert Table VIII about here***

\section{Multivariate Analysis}

Results of the regression analysis are presented in Table IX. The first column indicates the hypothesised sign for each coefficient. In Table IX, when controlling for price level, $M O N$ is negative in six cases and statistically significant in four of eight 
cases. This finding demonstrates that in-the-money contracts are less clustered than out-of-the money contracts, a finding that is not driven by the higher price level at which these contracts trade. ${ }^{14}$ We therefore show that the finding of Cheng et al. (2005) is mainly driven by the price level effect. Most importantly, the above finding confirms the intrinsic value hypothesis (see Table III). As the time value also reflects the speculative or "haziness" element of options values, clustering decreases with increasing moneyness.

****Insert Table IX about here***

The time-to-maturity (TTM) variable is negatively associated with price clustering in every case. In particular, TTM is negative and highly significant for quotes, while, for trades, the same relationship is found, albeit significant for the larger tick size only. This is clearly in line with hypothesis 1a in Table III, implying that price clustering increases when the need to conduct trades is more urgent. In options markets, it is assumed that the urgency to trade increases as expiry approaches.

The coefficient on $P L$ is highly significant for quotes and for all trades at the xx.50 tick. These results support our view that maturity and moneyness effects influence the distribution of ending prices in options, and that these are separate effects from the price level. This is reinforced by the fact that price level is not a significant factor for trades at the smaller tick size.

${ }^{14}$ The liquidity effect is also controlled for by $T S$ (transaction frequency). 
For firm size $(F S)$ there are negative and strongly significant coefficients for all trades and quotes under the xx.50 minimum price increment. For the smaller tick, a significant negative relationship exists only for put trades. ${ }^{15}$ However, the latter might be explained by the fact that for firms trading at the smaller tick size, a Designated Market Maker is assigned for $67 \%$ of observations, while for the larger tick size, this percentage falls to $55 \%$.

There is a highly significant negative relationship between volatility and price clustering for quotes, which is in contrast with the previous literature on index options contracts. For trades, the coefficient on volatility is only significant for puts at the xx.25 tick size and this has the expected sign.

The negotiation hypothesis also predicts that price clustering should decrease with the average trade size, reflecting the increased cost of utilising smaller price increments. The results reveal that for the xx.25 tick size, the negotiation hypothesis holds for both quotes and trades (in terms of the expected sign). For the larger tick size, a highly significant positive relationship is found for quotes and an insignificant relationship for trades.

Table IX gives mixed results on the signs of the DMM coefficients. For the xx.50 tick size, quotes are generally less clustered when designated market makers are assigned to assets. For the xx.25 tick size, the coefficients for quotes are positive and highly significant. The latter implies that quote price clustering tends to be significantly higher at the smaller tick for assets participating in the DMM scheme. When trades are considered, the results are only significant for the xx.25 puts,

\footnotetext{
${ }^{15}$ The average firm size is very similar for both tick sizes.
} 
showing that there is a substantial decrease in price clustering when designated market makers are assigned.

Transactions' frequency is very important in trade price clustering, consistent with the information asymmetry hypothesis. There is a strong and highly significant positive relationship between price clustering and $T F$ for all trades, reflecting the fact that market participants price assets more reliably by learning from previous trades (see Harris, 1991). The coefficients for quotes are not significant, which reflects the fact that quote frequency tends to be relatively consistent in this sample.

The coefficients for the opening dummy $(O D)$ are negative for quotes. However, the opposite is true in three cases for trades. The $C D$ coefficients show that price clustering is strongly influenced by the market close. This tends to conflict with the pattern predicted by the negotiation hypothesis. While trade prices are more clustered at the market open, they are not affected by the market close; in contrast, quotes are less clustered at the market open for the xx.50 tick size (consistent with Figure 1).

\section{CONCLUSIONS}

Individual equity options contracts have been repeatedly praised for their contribution to price discovery and are found to lead the process of accumulating new information in market prices (see Hull, 2008). However, as these contracts are often very low priced with a large minimum tick size, price clustering deteriorates the information content of trades. This is the first study of price clustering in individual equity options contracts. 
Prior studies (albeit on index options) have implicitly assumed that, similar to equity markets, there is a clear-cut relationship between price clustering and the price level (ap Gwilym et al., 1998a, Capelle-Blancard and Chaudhury, 2007). In contrast, we argue that options price clustering can be decomposed to price level, moneyness and maturity effects. Also, as the price level effect nests both the negotiation hypothesis and the price resolution theory, the findings are of particular importance for contract design and for assessing the price discovery process.

We assert that if the negotiation hypothesis holds, price clustering will increase close to expiry because of investors' increased urgency to conduct trades. In contrast, if the price resolution hypothesis holds, price clustering will decrease (asset is more correctly priced) as the intrinsic value increases as a proportion of price. Thus, there is a testable application for the negotiation versus the price resolution hypotheses.

For the relationship between price clustering and maturity, this paper's findings provide clear support for the negotiation hypothesis. There is an inverse relation between price clustering and maturity, which validates the hypothesis that when the need to conduct a trade is greater than the costs associated with price clustering, market participants will tend to use a smaller set of prices. The latter is independent of the price level because when maturity approaches, the price level will fall, all else being equal.

Price clustering also tends to be inversely related to moneyness. We argue that this moneyness effect is driven by an option's intrinsic value component. When moneyness is greater, intrinsic value is a higher proportion of option price. An increased intrinsic value component implies a greater certainty in option value, thus 
reducing price clustering. This element of the findings strongly supports the view that clustering decreases if valuation is less 'hazy' (Aitken et al, 1996).

For the larger tick size, (xx.50) trade price clustering increases with firm size, however, when the minimum tick size is $\mathrm{xx} .25$, a statistically significant relationship is only observed for put trades. Also, quote price clustering is significantly negatively related to volatility. Transaction frequency is strongly inversely related to clustering. Also, volume-based explanations of the relationship between price clustering and maturity/moneyness would lead to positive coefficients rather than the negative coefficients observed. The intraday clustering results show a higher level of clustering at the market open, which can be explained by information asymmetries that are accumulated overnight. The market close does not influence price clustering levels. There is mixed evidence on the influence of designated market makers on price clustering, with little impact evident in traded prices.

The paper fills a notable gap in the literature on options price clustering. The maturity and moneyness dimensions of options contracts are explicitly investigated as potential determinants of price clustering. The findings have important implications for contract design as price clustering can distort cross-valuation of options and their underlying assets, deteriorating price efficiency in both markets. 


\section{REFERENCES}

Aitken, M., Brown, P., Buckland, C., Izan, H., \& Walter, T. (1996). Price clustering on the Australian stock exchange. Pacific-Basin Finance Journal, 4, 297-314.

Anand, A., \& Weaver, D. G. (2006). The value of the specialist: Empirical evidence from the CBOE. Journal of Financial Markets, 9(2), 100-118.

ap Gwilym, O., Clare, A., \& Thomas, S. (1998a). Extreme price clustering in the London equity index futures and options markets. Journal of Banking \& Finance, 22(9), 1193-1206.

ap Gwilym, O., Clare, A., \& Thomas, S. (1998b). Price clustering and bid-ask spreads in international bond futures. Journal of International Financial Markets, Institutions and Money, 8, 377-391.

Ball, C., Torous, W., \& Tschoegl, A. (1985). The degree of price resolution - the case of the gold market. Journal of Futures Markets, 5(1), 29-43.

Bollerslev, T., \& Melvin, M. (1994). Bid-Ask spread and volatility in the foreign exchange market: An empirical analysis. Journal of International Economics, 36(3-4), 355-372.

Capelle-Blancard, G., \& Chaudhury, M. (2007). Price clustering in the CAC 40 index options market. Applied Financial Economics, 17(15), 1201-1210

Chakravarty, S., Gulen, H. \& Mayhew, S. (2004). Informed trading in stock and option markets. Journal of Finance, 3(6), 1235-1257. 
Cheng, K., Fung, J., \& Tse, Y. (2005). How electronic trading affects bid-ask spreads and arbitrage efficiency between index futures and options. Journal of Futures Markets, 25(4), 375-398.

Christie, W., \& Schultz, P. (1994). Why do Nasdaq market makers avoid odd-eighth quotes? Journal of Finance, 49(5), 1813-1840.

Chung, H., \& Chiang, S. (2006). Price clustering in E-mini and floor-traded index futures. Journal of Futures Markets, 26(3), 269-295.

Goodhart, C., \& Curcio, R. (1991). The clustering of bid/ask prices and the spread in the foreign exchange market. London School of Economics, Financial Market Group, Discussion Paper 110.

Harris, L. (1991). Stock price clustering and discreteness. Review of Financial Studies, 4(3), 389-415.

Hull, J. (2008). Options, futures and other derivatives (6th ed.). NJ: Prentice Hall.

McGroarty, F., ap Gwilym, O., \& Thomas, S. (2007). The components of electronic inter-dealer spot FX bid-ask spreads. Journal of Business, Finance \& Accounting, 34(9-10), 1635-1650.

Ni, S. X., Pearson, N. D., \& Poteshman, A. M. (2005). Stock price clustering on option expiration dates. Journal of Financial Economics, 78(1), 49-87.

Ohta, W. (2006). An analysis of intraday patterns in price clustering on the Tokyo Stock Exchange. Journal of Banking \& Finance, 30(3), 1023-1039.

Schwartz, A., Van Ness, B., \& Van Ness, R. (2004). Clustering in the futures market: Evidence from S\&P 500 futures contracts. Journal of Futures Markets, 24(5), 413-428.

Sheikh, A. M., \& Ronn, I. E. (1994). A characterization of the daily and intraday behavior of returns on options. Journal of Finance, 49(2), 557-579. 
Table I: Distribution of trade volume and trade frequency across moneyness levels and maturities

\begin{tabular}{|l|c|c|c|c|c|c|c|c|}
\hline & \multicolumn{9}{|c|}{ Moneyness } \\
\hline & \multicolumn{2}{|c|}{ In } & \multicolumn{2}{c|}{ At } & \multicolumn{2}{c|}{ Out } & \multicolumn{2}{c|}{ Total } \\
\hline Maturity & Volume & Frequency & Volume & Frequency & Volume & Frequency & Volume & Frequency \\
\hline Nearest & 213.07 & 7.78 & 1557.08 & 37.49 & 496.21 & 9.64 & 2266.36 & 54.90 \\
\hline 2nd Nearest & 84.49 & 2.94 & 762.86 & 20.12 & 635.77 & 10.97 & 1483.11 & 34.02 \\
\hline 3rd Nearest & 21.63 & 1.55 & 211.20 & 6.87 & 285.48 & 5.89 & 518.31 & 14.31 \\
\hline 4th Nearest & 10.89 & 0.44 & 74.82 & 1.59 & 100.08 & 1.75 & 185.79 & 3.78 \\
\hline Other & 20.02 & 0.29 & 101.40 & 0.66 & 135.13 & 0.92 & 256.55 & 1.87 \\
\hline Total & 350.09 & 13.00 & 2707.36 & 66.72 & 1652.67 & 29.16 & 4070.12 & 108.88 \\
\hline
\end{tabular}

Note. Volume refers to the total number of contracts traded. Frequency refers to the total number of trades. Figures are presented in thousands. Moneyness is calculated using equations 2 and 3. At-the-money (AT) options refer to prices that fall within the $(-0.05,0.05)$ moneyness range. 
Table II: Present values of the intrinsic value as a percentage of option price

\begin{tabular}{|l|l|c|c|}
\hline \multicolumn{2}{|c|}{} & \multicolumn{2}{c|}{ Option Type } \\
\hline Maturity & Moneyness & Call & Put \\
\hline \multirow{4}{*}{ Nearest } & DeepIn & 91.65 & 77.28 \\
\cline { 2 - 4 } & In & 87.58 & 82.11 \\
\cline { 2 - 4 } & At & 23.87 & 22.69 \\
\hline \multirow{4}{*}{ 3rd Nearest } & DeepIn & 88.55 & 77.45 \\
\cline { 2 - 4 } & In & 73.00 & 71.37 \\
\cline { 2 - 4 } & At & 11.20 & 13.28 \\
\hline \multirow{4}{*}{4 th Nearest } & DeepIn & 80.71 & 68.48 \\
\cline { 2 - 4 } & In & 63.30 & 62.55 \\
\cline { 2 - 4 } & At & 9.52 & 10.32 \\
\cline { 2 - 4 } & DeepIn & 80.55 & 68.82 \\
\cline { 2 - 4 } & At & 63.96 & 66.23 \\
\hline \multirow{3}{*}{ Other } & DeepIn & 8.85 & 8.92 \\
\cline { 2 - 4 } & In & 73.43 & 73.81 \\
\cline { 2 - 4 } & At & 45.19 & 61.03 \\
\hline \multirow{2}{*}{ Not For } & an & 4.92 & 8.34 \\
\hline
\end{tabular}

Note: For an explanation of how the IV component is calculated, see footnote 4. Moneyness is calculated using equations 2 and 3. At-themoney options refer to prices that fall within the $(-0.05,0.05)$ moneyness range and in-the-money refers to options that fall within the $[0.05,0.15)$ range. Deep-in-the money options (DeepIn) refer to prices with moneyness greater than 0.15 . The intrinsic value component of options is bounded below by zero. 


\begin{tabular}{llc}
\hline $\begin{array}{l}\text { Hypotheses } \\
\text { 1. Negotiation (Harris, 1991) }\end{array}$ & Effect & $\begin{array}{c}\text { Relation to Price } \\
\text { Clustering }\end{array}$ \\
1a. Negotiation in options & Maturity & + \\
2. Price resolution (Ball et al., 1985) & More information & - \\
2a. Price resolution in options & Maturity & + \\
2b. Price resolution in options (Cheng et al., 2005) & Moneyness & + \\
3. Intrinsic value & Moneyness & -
\end{tabular}

Note: Trading volume based explanations of the clustering-maturity and the clustering-moneyness relationships would be consistent with Hypotheses $2 \mathrm{a}$ and $2 \mathrm{~b}$ (as implied by Table I), i.e. positive signs would be expected. 
Table IV: Descriptive Statistics

\begin{tabular}{|c|c|c|c|c|c|c|c|c|c|}
\hline \multirow{2}{*}{ Name } & \multirow{2}{*}{ Tick } & \multicolumn{4}{|c|}{ Trades } & \multicolumn{4}{|c|}{ Quotes } \\
\hline & & $\mathrm{N}$ & MAX & MEAN & STD & $\mathrm{N}$ & MAX & MEAN & STD \\
\hline OAWS & 0.25 & 1716 & 98 & 15.30 & 12.66 & 1897211 & 150 & 22.81 & 12.11 \\
\hline OBBL & 0.25 & 5183 & 302 & 20.44 & 20.30 & 9605552 & 310 & 61.41 & 39.85 \\
\hline OBTG & 0.25 & 3994 & 59.75 & 9.01 & 8.34 & 3639392 & 101.25 & 21.73 & 15.52 \\
\hline OSAN & 0.25 & 2075 & 75 & 10.55 & 8.64 & 2177017 & 109.5 & 26.88 & 17.12 \\
\hline OTCO & 0.25 & 1999 & 86.25 & 13.20 & 11.55 & 1662975 & 103 & 26.90 & 18.32 \\
\hline OVOD & 0.25 & 5056 & 70.25 & 6.35 & 5.74 & 2775543 & 82.5 & 13.22 & 10.41 \\
\hline OAAM & 0.5 & 2382 & 748 & 63.83 & 72.14 & 3282337 & 1031.5 & 89.59 & 61.34 \\
\hline OAZA & 0.5 & 7873 & 928.5 & 74.30 & 74.79 & 14981191 & 1303.5 & 167.72 & 110.68 \\
\hline OBLT & 0.5 & 3371 & 242.5 & 36.41 & 30.94 & 2706553 & 291 & 63.02 & 39.75 \\
\hline OBOT & 0.5 & 2216 & 136 & 23.45 & 19.71 & 1476605 & 216 & 53.74 & 38.16 \\
\hline OBP & 0.5 & 6869 & 330.5 & 39.40 & 40.61 & 12240177 & 932.5 & 181.29 & 152.83 \\
\hline OBSK & 0.5 & 2716 & 182.5 & 19.38 & 18.98 & 1793260 & 183 & 48.31 & 36.40 \\
\hline OCPG & 0.5 & 1584 & 162 & 23.00 & 20.39 & 305136 & 250.5 & 32.51 & 20.78 \\
\hline OCUA & 0.5 & 3169 & 199 & 25.74 & 23.16 & 5159500 & 411.5 & 69.47 & 47.14 \\
\hline OEMG & 0.5 & 2558 & 682 & 67.29 & 69.85 & 2208592 & 682 & 86.04 & 54.17 \\
\hline OGNS & 0.5 & 3656 & 220 & 24.14 & 21.33 & 5267272 & 317.5 & 56.16 & 41.85 \\
\hline OGXO & 0.5 & 9516 & 621 & 40.53 & 36.41 & 8067020 & 761 & 72.97 & 48.17 \\
\hline OHSB & 0.5 & 5780 & 209.5 & 21.30 & 19.33 & 4543180 & 445.5 & 54.09 & 40.39 \\
\hline OKGF & 0.5 & 2434 & 152 & 24.03 & 20.40 & 717467 & 288 & 41.63 & 25.82 \\
\hline OLS & 0.5 & 1993 & 333 & 48.70 & 42.91 & 3526782 & 570.5 & 67.62 & 43.69 \\
\hline OPRU & 0.5 & 2833 & 206 & 31.17 & 28.14 & 6356484 & 560 & 111.02 & 77.89 \\
\hline ORBS & 0.5 & 8166 & 367 & 46.30 & 42.49 & 15620181 & 726 & 133.18 & 97.94 \\
\hline ORTZ & 0.5 & 5069 & 1001 & 77.56 & 90.24 & 6185706 & 1332.5 & 130.94 & 92.85 \\
\hline ORUT & 0.5 & 2151 & 218 & 31.50 & 25.73 & 3386466 & 380.5 & 81.38 & 62.76 \\
\hline OSCB & 0.5 & 2765 & 380.5 & 42.04 & 40.72 & 4101801 & 527 & 65.65 & 40.59 \\
\hline OSPW & 0.5 & 1938 & 162 & 19.17 & 17.59 & 740680 & 162 & 37.67 & 27.19 \\
\hline OTSB & 0.5 & 7224 & 320 & 31.68 & 31.59 & 4259098 & 572.5 & 81.24 & 62.09 \\
\hline OTAB & 0.5 & 2600 & 400 & 36.93 & 37.74 & 4520586 & 601.5 & 58.50 & 39.70 \\
\hline
\end{tabular}

Note. Mean refers to the average price per asset over the sample period. STD refers to standard deviation.

Tick is also the minimum price over the sample period. 
Table V: Percentage of Prices at Integer Values

\begin{tabular}{|c|c|c|c|c|c|c|}
\hline \multicolumn{7}{|c|}{ Panel 1} \\
\hline & \multicolumn{6}{|c|}{$\times x .50$} \\
\hline & \multicolumn{2}{|c|}{ Quote } & & \multicolumn{3}{|c|}{ Trade } \\
\hline Name & Obs. & Perc. & ChiSq & Obs. & Perc. & ChiSq \\
\hline OAAM & $2,349,257$ & $71.57 * * *$ & $18.62 * * *$ & 1,554 & $65.24 * * *$ & $9.29 * * *$ \\
\hline OAZA & $8,547,309$ & 57.05 & 1.99 & 5,265 & $66.87 * * *$ & $11.39 * * *$ \\
\hline OBLT & $2,171,328$ & $80.22 * * *$ & $36.54 * * *$ & 2,084 & $61.82 * *$ & $5.59 * *$ \\
\hline OBOT & $1,121,677$ & $75.96 * * *$ & $26.96 * * *$ & 1,380 & $62.27 * * *$ & $6.03 * * *$ \\
\hline OBP & $6,645,004$ & 54.29 & 0.74 & 4,395 & $63.98 * * *$ & $7.82 * * *$ \\
\hline OBSK & $1,341,319$ & $74.80 * * *$ & $24.60 * * *$ & 1,540 & 56.70 & 1.80 \\
\hline OCPG & 152,929 & 50.12 & $<0.01$ & 955 & $60.29 * *$ & $4.24 * *$ \\
\hline OCUA & $2,700,364$ & 52.34 & 0.22 & 1,845 & $58.22 *$ & $2.70^{*}$ \\
\hline OEMG & $1,447,848$ & $65.56 * * *$ & $9.68 * * *$ & 1,697 & $66.34 * * *$ & $10.68 * * *$ \\
\hline OGNS & $2,936,996$ & 55.76 & 1.33 & 2,080 & 56.89 & 1.90 \\
\hline OGXO & $4,869,642$ & $60.36 * *$ & $4.30 * *$ & 5,764 & $60.57 * *$ & $4.47 * *$ \\
\hline OHSB & $2,536,838$ & 55.84 & 1.36 & 3,207 & 55.48 & 1.20 \\
\hline OKGF & 490,055 & $68.30 * * *$ & $13.40 * * *$ & 1,641 & $67.42 * * *$ & $12.14 * * *$ \\
\hline OLS & $2,362,217$ & $66.98 * * *$ & $11.53 * * *$ & 1,202 & $60.31 * *$ & $4.25^{* *}$ \\
\hline OPRU & $3,292,328$ & 51.79 & 0.13 & 1,765 & $62.30 * * *$ & $6.05 * * *$ \\
\hline ORBS & $8,338,298$ & 53.38 & 0.46 & 4,932 & $60.40 * *$ & $4.32 * *$ \\
\hline ORTZ & $3,948,658$ & $63.84 * * *$ & $7.66^{* * * *}$ & 3,425 & $67.57 * * *$ & $12.34 * * *$ \\
\hline ORUT & $2,062,673$ & $60.91 * *$ & $4.76^{* *}$ & 1,297 & $60.30 * *$ & $4.24 * *$ \\
\hline OSCB & $2,729,508$ & $66.54 * *$ & $10.95^{* *}$ & 1,648 & $59.60 * *$ & $3.69 * *$ \\
\hline OSPW & 560,749 & $75.71 * * *$ & $26.43 * * *$ & 1,124 & 58.00 & 2.56 \\
\hline OTAB & $2,653,830$ & $58.71 *$ & $3.03 *$ & 1,490 & 57.31 & 2.14 \\
\hline OTSB & $2,542,998$ & $59.71 * *$ & $3.77 * *$ & 4,530 & $62.71 * * *$ & $6.46 * * *$ \\
\hline Total & $65,801,825$ & 59.04 & . & 54,820 & 61.69 & . \\
\hline \multicolumn{7}{|c|}{ Panel 2} \\
\hline & \multicolumn{6}{|c|}{ xx. 25} \\
\hline & \multicolumn{2}{|c|}{ Quote } & & \multicolumn{3}{|c|}{ Trade } \\
\hline Name & Obs. & Perc. & ChiSq & Obs. & Perc. & ChiSq \\
\hline OAWS & 545,424 & 28.75 & 2.08 & 648 & $37.76 * * *$ & $12.96 * * *$ \\
\hline OBBL & $3,478,005$ & $36.21 * *$ & $7.74 * *$ & 2,069 & $39.92 * * *$ & $15.67 * * *$ \\
\hline OBTG & 960,743 & 26.40 & 0.29 & 1,254 & 31.40 & 3.58 \\
\hline OSAN & 770,567 & $35.40 * *$ & $10.20 * *$ & 759 & $36.58 * * *$ & $10.91 * * *$ \\
\hline OTCO & 680,379 & $40.91 * * *$ & $20.19 * * *$ & 622 & 31.12 & 4.35 \\
\hline OVOD & 741,775 & 26.73 & 0.37 & 1,478 & 29.23 & 1.50 \\
\hline Total & $7,176,893$ & 32.89 & . & 6,830 & 34.15 & 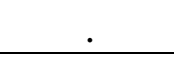 \\
\hline
\end{tabular}

Note. Tick Size refers to the minimum price increment. The optimal distribution for tick of xx.25 (xx.50) is $25 \%(50 \%)$. ChiSq refers to the $x^{2}$ test statistic. *, **, *** significant at the $10 \%$, 5\% and $1 \%$ levels, respectively. Perc. denotes percentage of prices at integers. 
Table VI: Price and Size Level Clustering

\begin{tabular}{|c|c|c|c|c|}
\hline \multicolumn{5}{|c|}{ Panel 1: Price } \\
\hline & \multicolumn{4}{|c|}{ xx. 25} \\
\hline \multirow{2}{*}{ Quartile } & \multicolumn{2}{|c|}{ Quotes } & \multicolumn{2}{|c|}{ Trades } \\
\hline & Obs. & Perc. & Obs. & Perc \\
\hline $0-25 \%$ & $3,356,437$ & 28.53 & 6,148 & 33.58 \\
\hline $26-75 \%$ & $3,627,129$ & 38.03 & 678 & 39.65 \\
\hline \multirow[t]{2}{*}{$76-100 \%$} & 193,327 & 42.31 & 4 & 57.14 \\
\hline & \multicolumn{4}{|c|}{ xx.50 } \\
\hline $0-25 \%$ & $11,079,133$ & 50.91 & 29,147 & 58.94 \\
\hline $26-75 \%$ & $35,928,104$ & 63.29 & 22,975 & 64.88 \\
\hline $76-100 \%$ & $18,794,588$ & 57.10 & 2,698 & 67.48 \\
\hline \multicolumn{5}{|c|}{ Panel 2: Size } \\
\hline & \multicolumn{4}{|c|}{ xx. 25} \\
\hline \multirow{2}{*}{ Quartile } & \multicolumn{2}{|c|}{ Quotes } & \multicolumn{2}{|c|}{ Trades } \\
\hline & Obs. & Perc & Obs. & Perc \\
\hline $0-25 \%$ & 697,253 & 24.50 & 3,034 & 35.55 \\
\hline $26-75 \%$ & $2,597,285$ & 26.47 & 1,862 & 34.25 \\
\hline \multirow[t]{2}{*}{$76-100 \%$} & $3,882,355$ & 42.67 & 1,934 & 31.96 \\
\hline & \multicolumn{4}{|c|}{ Xx.50 } \\
\hline $0-25 \%$ & $22,160,553$ & 55.79 & 36,255 & 61.55 \\
\hline $26-75 \%$ & $32,404,712$ & 58.92 & 12,240 & 61.42 \\
\hline $76-100 \%$ & $11,236,560$ & 67.18 & 6,325 & 63.02 \\
\hline
\end{tabular}

Note. Perc. denotes percentage of prices at integers. 
Table VII: Expiration Dates Clustering

\begin{tabular}{|c|c|c|c|c|c|c|}
\hline Tick & \multicolumn{7}{|c|}{ xx.25 } \\
\hline \multirow{2}{*}{ Date/Type } & \multicolumn{7}{|c|}{ Quotes } & \multicolumn{3}{c|}{ Trades } \\
\cline { 2 - 7 } & Obs. & Perc. & ChiSq & Obs. & Perc. & ChiSq \\
\hline Day & 28,086 & 36.71 & $8.43^{* *}$ & 72 & 38.50 & $29.49^{* * *}$ \\
\hline Week & 402,572 & 35.24 & $7.20^{*}$ & 436 & 33.77 & 4.20 \\
\hline Other & $6,746,235$ & 32.85 & 4.29 & 6,322 & 34.09 & 6.25 \\
\hline \multicolumn{7}{|c|}{ xx.50 } \\
\hline Day & 229,940 & 63.10 & $6.86^{* * *}$ & 447 & 58.66 & $3.00^{*}$ \\
\hline Week & $3,478,820$ & 62.69 & $6.44 * * *$ & 3,361 & 58.38 & $2.81 *$ \\
\hline Other & $62,093,065$ & 58.84 & $3.12^{*}$ & 51,012 & 61.95 & $5.71^{* *}$ \\
\hline
\end{tabular}

Note. Perc. denotes percentage of prices at integers. $*$, **, *** significant at the $10 \%, 5 \%$ and $1 \%$ levels, respectively. 
Table VIII: Price Clustering by Tick Size, Option Type, Trade Type, Maturity and Moneyness

\begin{tabular}{|c|c|c|c|c|c|c|c|c|c|c|c|c|c|c|c|c|c|}
\hline \multicolumn{10}{|c|}{ xx. 25} & \multirow{2}{*}{\multicolumn{8}{|c|}{$\begin{array}{c}\text { xx.50 } \\
\text { Option Type }\end{array}$}} \\
\hline & & \multicolumn{8}{|c|}{ Option Type } & & & & & & & & \\
\hline & & \multicolumn{4}{|c|}{ Call } & \multicolumn{4}{|c|}{ Put } & \multicolumn{4}{|c|}{ Call } & \multicolumn{4}{|c|}{ Put } \\
\hline & & \multicolumn{2}{|c|}{ Quotes } & \multicolumn{2}{|c|}{ Trade } & \multicolumn{2}{|c|}{ Quotes } & \multicolumn{2}{|c|}{ Trade } & \multicolumn{2}{|c|}{ Quotes } & \multicolumn{2}{|c|}{ Trade } & \multicolumn{2}{|c|}{ Quotes } & \multicolumn{2}{|c|}{ Trade } \\
\hline Maturity & Moneyness & Obs. & Perc. & Obs. & Perc. & Obs. & Perc. & Obs. & Perc. & Obs. & Perc. & Obs. & Perc. & Obs. & Perc. & Obs. & Perc. \\
\hline \multirow{3}{*}{ Nearest } & In & 990,371 & 39.25 & 369 & 32.86 & 927,694 & 42.94 & 218 & 35.68 & $6,759,456$ & 67.98 & 2,675 & 66.61 & $5,303,801$ & 71.64 & 1,345 & 66.19 \\
\hline & At & 357,952 & 29.15 & 1,265 & 34.41 & 339,108 & 29.43 & 1,028 & 34.01 & $5,103,958$ & 61.28 & 10,154 & 60.97 & $4,990,470$ & 61.78 & 8,673 & 61.36 \\
\hline & Out & 63,854 & 26.63 & 263 & 31.09 & 71,893 & 30.22 & 220 & 31.34 & 809,246 & 51.76 & 1,965 & 57.66 & 925,540 & 51.20 & 2,693 & 57.54 \\
\hline \multirow{3}{*}{$\begin{array}{l}\text { 2nd } \\
\text { Nearest }\end{array}$} & In & 799,587 & 37.13 & 122 & 36.97 & 712,171 & 38.74 & 116 & 33.53 & $4,959,877$ & 61.52 & 789 & 63.17 & $3,896,796$ & 63.91 & 680 & 67.19 \\
\hline & At & 361,788 & 29.36 & 569 & 32.64 & 324,310 & 29.09 & 690 & 35.77 & $4,603,614$ & 59.02 & 5,189 & 61.97 & $4,296,775$ & 59.48 & 5,086 & 63.01 \\
\hline & Out & 139,477 & 27.24 & 387 & 35.47 & 125,439 & 26.38 & 206 & 32.85 & $1,682,082$ & 53.52 & 2,549 & 59.79 & $1,786,633$ & 52.93 & 3,024 & 60.65 \\
\hline \multirow{2}{*}{$\begin{array}{l}\text { 3rd } \\
\text { Nearest }\end{array}$} & At & 190,858 & 27.07 & 225 & 30.99 & 158,058 & 26.42 & 278 & 37.12 & $2,412,592$ & 57.47 & 1,559 & 61.79 & $2,077,089$ & 57.61 & 1,844 & 64.14 \\
\hline & Out & 104,129 & 26.08 & 143 & 31.50 & 95,311 & 25.86 & 154 & 28.73 & $1,344,942$ & 54.34 & 1,366 & 61.26 & $1,352,489$ & 53.46 & 1,658 & 62.17 \\
\hline \multirow{3}{*}{$\begin{array}{l}\text { 4th } \\
\text { Nearest }\end{array}$} & In & 139,817 & 25.42 & 16 & 30.77 & 89,216 & 26.25 & 25 & 32.89 & $1,128,312$ & 49.93 & 91 & 60.26 & 759,568 & 50.05 & 105 & 65.22 \\
\hline & At & 53,061 & 26.06 & 60 & 38.96 & 46,472 & 26.45 & 50 & 36.76 & 703,336 & 50.23 & 419 & 63.58 & 585,458 & 50.28 & 395 & 62.01 \\
\hline & Out & 41,074 & 25.27 & 56 & 43.41 & 43,541 & 25.59 & 91 & 46.67 & 434,870 & 50.11 & 447 & 63.58 & 416,606 & 50.06 & 453 & 62.74 \\
\hline \multirow{3}{*}{ Other } & In & 102,889 & 26.39 & 13 & 43.33 & 74,770 & 26.32 & 12 & 19.35 & $1,513,260$ & 50.08 & 67 & 60.91 & $1,134,503$ & 49.98 & 53 & 58.89 \\
\hline & At & 47,344 & 26.54 & 26 & 38.81 & 40,209 & 26.97 & 25 & 40.32 & 728,352 & 50.09 & 171 & 68.13 & 574,630 & 49.93 & 183 & 65.12 \\
\hline & Out & 55,775 & 27.28 & 30 & 36.59 & 46,499 & 27.41 & 34 & 39.53 & 768,087 & 50.22 & 163 & 53.44 & 539,717 & 50.19 & 301 & 67.19 \\
\hline
\end{tabular}

Note. Perc. denotes percentage of prices at integers. 
Table IX: OLS Regressions by Tick Size, Option and Trade Type

\begin{tabular}{|c|c|c|c|c|c|c|c|c|}
\hline & \multicolumn{4}{|c|}{ Quotes } & \multicolumn{4}{|c|}{ Trades } \\
\hline & \multicolumn{2}{|c|}{$\mathrm{xx} .25$} & \multicolumn{2}{|c|}{ хx.50 } & \multicolumn{2}{|c|}{ xx. 25} & \multicolumn{2}{|c|}{$\times x .50$} \\
\hline & Call & Put & Call & Put & Call & Put & Call & Put \\
\hline \multirow[t]{2}{*}{ Intercept (.) } & $13.73 * * *$ & $-3.88 * *$ & $90.37 * * *$ & $88.58 * * *$ & 7.95 & $23.58 * * *$ & $48.01 * * *$ & $40.34 * * *$ \\
\hline & 13.59 & -2.72 & 91.98 & 111.67 & 1.41 & 3.10 & 18.70 & 15.97 \\
\hline \multirow[t]{2}{*}{ MON (+ vs. -) } & $-57.43 * * *$ & $-54.08 * * *$ & $7.48 * *$ & 1.53 & $-48.73 * * *$ & -1.46 & $-3.36 * * *$ & -4.48 \\
\hline & -17.56 & -12.44 & 1.93 & 1.16 & -3.34 & -0.08 & -2.47 & -1.06 \\
\hline \multirow[t]{2}{*}{ TTM (+ vs. -) } & $-0.13 * * *$ & $-0.14 * * *$ & $-0.09 * * *$ & $-0.10 * * *$ & -0.01 & -0.02 & $-0.01 * * *$ & $-0.01 * * *$ \\
\hline & -39.05 & -31.25 & -71.00 & -95.15 & -0.59 & -1.42 & -4.97 & -2.65 \\
\hline \multirow[t]{2}{*}{ PL (+) } & $0.59 * * *$ & $0.67 * * *$ & $0.04 * * *$ & $0.05 * * *$ & 0.05 & $-0.09 *$ & $0.04 * * *$ & $0.04 * * *$ \\
\hline & 43.86 & 48.45 & 14.75 & 27.95 & 1.06 & -1.74 & 8.18 & 7.35 \\
\hline \multirow[t]{2}{*}{ FS (-) } & $4.71 * * *$ & $7.27 * * *$ & $-1.39 * * *$ & $-1.21 * * *$ & -0.28 & $-2.63 * *$ & $-1.27 * * *$ & $-0.61 * *$ \\
\hline & 33.60 & 35.00 & -10.65 & -12.75 & -0.35 & -2.47 & -4.59 & -2.36 \\
\hline \multirow[t]{2}{*}{ Vol (+) } & $-132.87 * * *$ & $-167.45^{* * *}$ & $-19.56 * * *$ & $-11.85 * * *$ & 12.84 & $77.74 * * *$ & -0.15 & 0.23 \\
\hline & -24.66 & -28.66 & -18.00 & -10.12 & 0.51 & 2.95 & -0.04 & 0.06 \\
\hline \multirow[t]{2}{*}{ TS (-) } & $-3.25 \mathrm{E}-03$ & $-0.01 * * *$ & $0.18 * * *$ & $0.19 * * *$ & $-0.01 * *$ & -0.01 & $4.05 \mathrm{E}-03$ & 0.01 \\
\hline & -1.39 & -4.86 & 18.29 & 40.44 & -2.10 & -1.51 & 0.66 & 1.19 \\
\hline \multirow[t]{2}{*}{ DMM (-) } & $23.10 * * *$ & $32.12 * * *$ & $-4.09 * * *$ & $-5.88 * * *$ & $0.46 * * *$ & $-19.20 * * *$ & $0.66 * * *$ & $-1.03 * * *$ \\
\hline & 19.51 & 22.25 & -11.76 & -15.45 & 0.08 & -2.98 & 0.57 & -0.77 \\
\hline \multirow[t]{2}{*}{$\mathrm{TF}(+)$} & -0.26 & 0.09 & 0.17 & -0.07 & $91.01 * * *$ & $93.88 * * *$ & $61.77 * * *$ & $62.63 * * *$ \\
\hline & -1.23 & 0.42 & 1.25 & -0.54 & 49.64 & 50.30 & 89.51 & 89.03 \\
\hline \multirow[t]{2}{*}{$\mathrm{OD}()}$. & $-0.64 * *$ & -0.29 & $-3.42 * * *$ & $-3.21 * * *$ & 3.29 & $4.07 * *$ & -0.40 & $1.97 * * *$ \\
\hline & -2.00 & -0.89 & -15.03 & -14.37 & 1.45 & 1.94 & -0.56 & 2.73 \\
\hline \multirow[t]{2}{*}{$\mathrm{CD}()}$. & 0.12 & 0.20 & 0.12 & -0.01 & -0.74 & 0.14 & 0.30 & 0.58 \\
\hline & 0.52 & 0.80 & 0.78 & -0.05 & -0.55 & 0.12 & 0.54 & 1.07 \\
\hline
\end{tabular}




\begin{tabular}{|l|c|c|c|c|c|c|c|c|} 
R-Squared & 0.37 & 0.43 & 0.31 & 0.32 & 0.53 & 0.58 & 0.34 & 0.35 \\
\hline No. of Obs. & 12202 & 12210 & 44384 & 44401 & 2068 & 1998 & 13330 & 13585 \\
\hline
\end{tabular}

Clust $_{i t y x}=\alpha_{1}+a_{2}$ MON $_{i t x}+a_{3}$ TTM $_{i z x}+a_{4}$ PL $_{i z-1}+a_{5} F_{i z}+a_{6} V_{i t x}$ $+a_{7} T_{i t x}+a_{8} \mathrm{DMM}_{i}+a_{9} \mathrm{TF}_{i t x}+a_{10} O D_{t}+a_{111} C D_{t}+\varepsilon_{i t y x}$

Note. Where $i=$ option contract, $t=$ intraday interval, $z=$ daily price, $y=$ quote/trade, $x=$ call/put. Clustity $x$, is the percentage of trades at integers at each time interval $t(t=1,2, \ldots 2052)$, for $i=28$ contracts and is different for $x=$ calls and puts and $y=$ quotes and trades. MON is the average moneyness measure per contract at every interval; TTM is the average time to maturity for options traded at each time interval; $P L$ is the average trade price level at each time interval per contract; $F S$ denotes the firm size as the natural log of market capitalization per day for each contract; VOL denotes volatility for the at-the-money, nearest-to-mature contract; TS is the average trade size at each time interval per contract; $D M M$ is the Designated Market Maker dummy; $T F$ denotes the transaction frequency at each time interval as the inverse square root of the number of transactions per day for each call and put contract. $O D$ and $C D$ are the open and close dummies respectively. *,**,*** significant at the $10 \%, 5 \%$ and $1 \%$ levels, respectively. T-statistics are reported (based on Newey-West HAC standard errors). Predicted sign in parentheses. (+ vs. -) denotes competing hypotheses being tested. 
Figure 1: Intraday Clustering Pattern by Tick Size

\section{$x \times .25$}

------ Quote $\quad---$ Trade

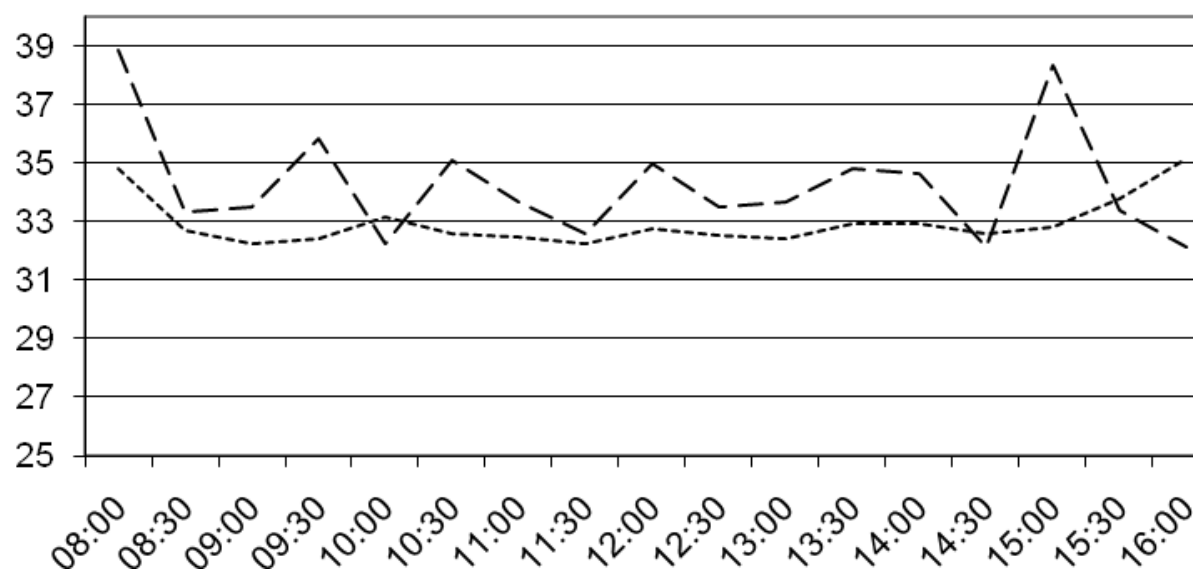

$x \times .50$

Quote $\quad---$ Trade

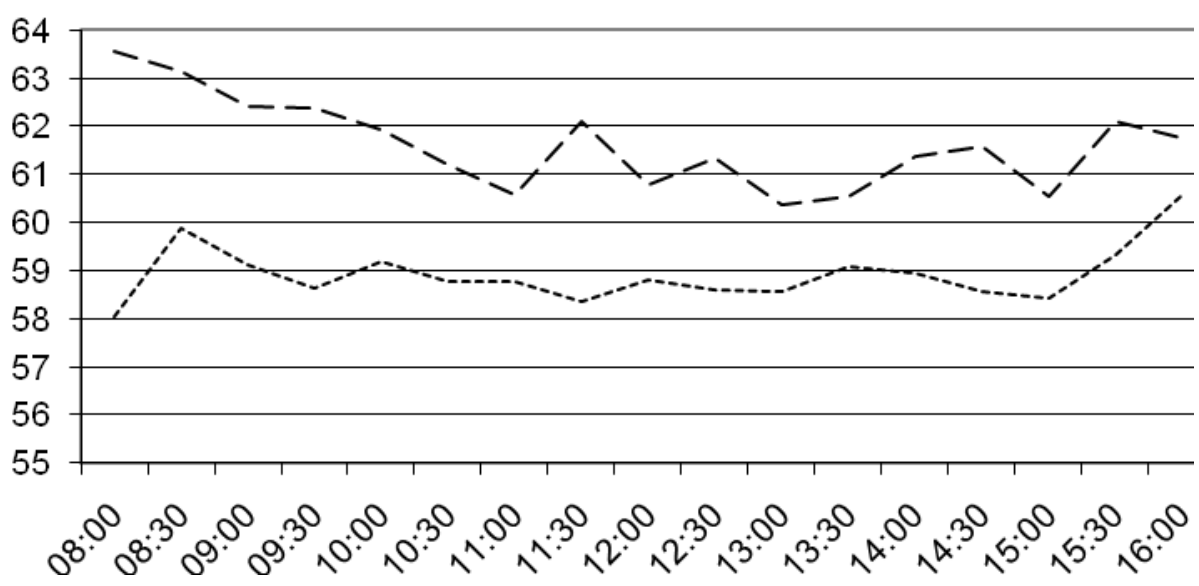


